\title{
Configuring Masculinity
}

\author{
STEFAN HORLACHER
}

\begin{abstract}
More than just an Introduction to the contributions which make up this volume, this article argues that masculinity studies is a social necessity, points to the problems the construction of male gender identities seems to pose (not only) in the twentieth and twenty-first centuries and stresses the outstanding contribution that literature can make with regard to male gender identity formation. Moreover, this contribution asks whether gender identity should not be seen as a potentially unstable, contradictory, and evolving cultural product akin to literature, whose medium, language, and chief "mode of operation", that is, narration, it shares. The article also contends that in literary texts, we find both, self- as well as externally-determined or enforced configurations of masculinity as well as the very mechanisms of their production or enforcement.
\end{abstract}

Masculinity studies is not a conservative backlash but a social necessity. ${ }^{1}$ While gender, women's, and feminist studies have been at least partly institutionalized and can look back into their own history - or histories - as (albeit sometimes contested) academic disciplines, the subject of masculinity has only much later begun to receive the attention of the academy. If, initially, masculinity was hardly more than an occasional topic in disciplines such as sociology, psychology, history, and literary studies, in the meantime it has become a field of study in its own right, at least in the US and the UK.

\footnotetext{
${ }^{1}$ It is necessary to clearly differentiate between current forms of "masculinity studies" or "critical studies on men and masculinities" to which I refer, and more conservative and reactionary perspectives which can rightly be considered as backlashes.
} 
This genesis of masculinity studies as a new field of research can be explained by the centuries in which, in real life as well as in research, masculinity had been more or less invisible, given that the traditional "overgeneralization from male to generic human experience" not only distorted the "understanding of what, if anything, is truly generic to humanity but also preclude[d] the study of masculinity as a specific male experience, rather than a universal paradigm for human experience". ${ }^{2}$

The fact that "notions of the 'human' ... obscure notions of the "masculine"" explains why (notwithstanding Freud and his emphasis on masculinity as "normalcy") masculinity remained something of an unmarked (and therefore invisible) gender in political, social, and cultural contexts.

However, whenever masculinity has become visible in the late twentieth and early twenty-first centuries, it has regularly presented an alarming picture, frequently mentioned in connection with violent incidents such as the Anders Behring Breivik massacres in Norway or shootings in universities and schools. In the current debate on education, at least in Germany, masculinity has been pronounced to be a problem: the latest statistics of the Federal Government and the World Health Organization (WHO) show men ${ }^{4}$ to be at a significantly higher risk of lapsing into alcoholism, exhibiting personality disorders and committing suicide.

Also with regard to life expectancy, chronic disorders, and the need for long-term care, men have been shown to be seriously disadvantaged. ${ }^{5}$ If one follows media coverage, one could almost have the

\footnotetext{
${ }^{2}$ Harry Brod, "Introduction: Themes and Theses of Men's Studies", in The Making of Masculinities: The New Men's Studies, ed. Harry Brod, Boston: Allen and Unwin, 1987, 2 (emphases in the original).

${ }^{3}$ David Rosen, The Changing Fictions of Masculinity, Urbana: University of Illinois Press, 1993, xi-xii.

${ }^{4}$ Given the impressive work done in queer, intersex, and transgender studies, it seems necessary to inquire critically into concepts or definitions of masculinity and femininity at use in these statistics. If they are nevertheless mentioned here, it is mainly as a demonstration that the problem of what traditional models of "being a man" entail has reached public consciousness.

${ }^{5}$ See Doris Bardehle, "Gesundheit und gesundheitliche Versorgung von Männern", in Erster Deutscher Männergesundheitsbericht: Ein Pilotbericht, eds Doris Bardehle and Matthias Stiehler, Munich: Zuckschwerdt, 2010, 17-27; Männergesundheitsbericht 2013, eds Lothar Weißbach and Matthias Stiehler, Bern: Huber, 2013; HansJoachim Lenz, “Zwischen Men's Studies und männlicher Verletzungsoffenheit - Zur
} 
impression that the formerly strong sex is about to become the new weaker sex, ${ }^{6}$ mainly characterized by numerous physical and mental weaknesses ${ }^{7}$ - which brings me back to the very first sentence of this article, that is, the social necessity of what is called "masculinity studies" or "critical studies on men and masculinities". By this, I mean current research on masculinity as portrayed in the surveys by Todd Reeser, Raewyn Connell, and Stefan Horlacher, ${ }^{8}$ but most explicitly not the more conservative and reactionary perspectives, such as the men's rights perspective, the mythopoetic perspective, morally and socio-biologically conservative perspectives, or the Evangelical Christian Men's Movement (Promise Keepers). ${ }^{9}$

Many of the most influential approaches in contemporary masculinity studies are heavily influenced by sociological, historical, literary, and allegedly neutral biomedical knowledge. They collect and analyze gender-specific data with regard to violent behavior, life expectancy, drug abuse, and the susceptibility to particular diseases. Although archaic and obsolete images of men linking masculinity to risk-taking and dare-devil behavior have been called into question for decades, the old stereotypes, lurking everywhere, prove to be almost insurmountable. This has led to some kind of paradox: while current research has shown that in post-modern societies the construction of a monolithic or singular male gender identity has become problematic and increasingly impossible, the construction of a male gender identity based on the premises of an unrestricted plurality has turned out to be problematic and crises-ridden as well.

kurzen Geschichte der Männerforschung in Deutschland", Männer und Geschlecht: Freiburger GeschlechterStudien, XXI (2007), 41-77; Rainer Emig and Antony Rowland, Introduction, in Performing Masculinity, eds Rainer Emig and Antony Rowland, Houndmills: Palgrave Macmillan, 2010, 1-12.

${ }^{6}$ See Emig and Rowland, Introduction, 7-8; George Yúdici, "What's a Straight Man to Do?", in Constructing Masculinity, eds Maurice Berger, Wallis Brian and Simon Watson, New York: Routledge, 1995, 267-83.

${ }^{7}$ See Elisabeth Badinter, XY: Die Identität des Mannes, Munich: Piper, 1993, 49-50.

${ }^{8}$ See Todd Reeser's and Raewyn Connell's contributions in this volume; also Stefan Horlacher, "Masculinity Studies: Contemporary Approaches and Alternative Perspectives", in Beyond Gender: Future(s) of Women's/Feminist/Men's/Queer/Intersectionality Studies, eds Greta Olson, Daniel Hartley, Mirjam Horn, and Regina Schmidt, New York: Palgrave, under review.

${ }^{9}$ See Kenneth Clatterbaugh, Contemporary Perspectives on Masculinity: Men, Women, and Politics in Modern Society, Boulder, CO: Westview, 1997. 
In this context, Peter F. Murphy has correctly emphasized the role "[that] literature has played in reinforcing the assumptions about masculinity and, at times, [in] helping to establish the norm of manhood"; ${ }^{10}$ additionally, Vera Nünning has succinctly stated the outstanding contribution that literature - fictional constructions of masculinity - can make with regard to male gender identity formation when she stresses the "immense social and cultural relevance" of masculinity concepts that are "disseminated and to some extent critiqued" in literature as well as in non-fictional texts. ${ }^{11}$ Especially when discussing a potential crisis of masculinity, literary discourses become a privileged site for registering patriarchy's "loss of legitimacy" and how "different groups of men are now negotiating this loss in very different ways". ${ }^{12}$

If Murphy argues that literature can offer alternatives, that is, "other images, other roles, other options for men and masculinity", 13 we should not err by restricting this knowledge to the representative (if not normative) aspect of artistic works, but address the much more fundamental question concerning the extent and tendency of art especially literature - to possess a kind of knowledge about masculinity that is not only relevant for a better understanding of its construction or specific configuration, functioning, and supposed defects, but also features a co-constructive potential which enables the reader to critically re-construct their masculinity.

Over the last years, it is especially at the intersection of history and literature that interesting new results about masculinity have emerged, leading to a multitude of studies that focus on demythologizing the history of everyday life on a micro-structural level. These studies have produced what Clifford Geertz calls "thick descriptions" of "simple" narratives that question the validity of dominant master narratives of masculinity. In most of the disciplines dealing with masculinity and gender there has been a shift in focus towards narrative modes and structures, that is, to stories and genres as the most important components of the historical and current configuration of mas-

\footnotetext{
${ }^{10}$ Peter F. Murphy, "Introduction: Literature and Masculinity", in Fictions of Masculinity: Crossing Cultures, Crossing Sexualities, ed. Peter F. Murphy, New York: New York University Press, 1994, 1.

${ }^{11}$ See Vera Nünning, "Sammelrezension", Anglia, CXX/2 (November 2002), 301.

${ }^{12}$ R.W. Connell, Masculinities, 2nd edn, Cambridge: Polity, 2005, 202.

${ }^{13}$ Murphy, "Introduction: Literature and Masculinity", 1.
} 
culinities. ${ }^{14}$ "Narration" is about to become a key concept for the study of masculinity not only within British, American, and German Literary and Cultural Studies but also in sociology, history, and psychoanalysis. This shift towards narrative could be crucial for the further development of masculinity studies and for any endeavor to overcome the increasing fragmentation and partitioning of the field. From this perspective, masculinity - or, to be more precise, important aspects of masculinity - could be conceptualized and understood as a narrative which takes on different forms in different contexts and at different times. If language, narrative, literature, and gender identity are as intimately linked as this approach suggests, gender identity could probably best be conceived of as a narration that is constantly characterized by a certain fluidity or instability, by a precarious emplotment and a negotiation of change and mutability, with the postulation of a true gender identity being nothing but a regulatory fiction. ${ }^{15}$

Gender identity could then be seen as a potentially unstable, contradictory, and evolving cultural product akin to language and the narrative operations of literature. Without refuting its biological substratum and questions of embodiment, gender identity could then be understood as being created through a metaphorical act of writing that produces its precarious "unity" 16 and renders it a "narrative artifice, privileging a presence, or identity, that does not exist outside language". ${ }^{17}$ If this assumption is correct, then the literary text, this "ever-changing and interactive storehouse of knowledge for living", ${ }^{18}$ could really be seen as a privileged space and epistemological medium

\footnotetext{
${ }^{14}$ Narrative is here not restricted to literary and cultural artifacts but extends from the construction of individual gender identity by way of biographical, material and embodied social processes to collective national identities and images.

${ }^{15}$ See Judith Butler, Gender Trouble: Feminism and the Subversion of Identity, New York: Routledge, 1990, 141; also Bettina Schötz's contribution in this volume.

16 "Unity" refers here to the individual person's construction of a flexible gender identity over a lifetime and not to one single or stable concept of masculinity, femininity, etc.

${ }^{17}$ Sidonie Smith, A Poetics of Women's Autobiography: Marginality and the Fictions of Self-Representation, Bloomington, 1987, 5; see also Michael Bamberg, "Identity and Narration", in The Living Handbook of Narratology, eds Peter Hühn et al., Hamburg: Hamburg University, 23 July 2014: http://www.lhn.uni-hamburg.de/article/ identity-and-narration.

${ }^{18}$ Ottmar Ette, "Literature as Knowledge for Living, Literary Studies as Science for Living", trans. and ed. with an Introduction, Vera M. Kutzinski, PMLA, CXXV/4 (October 2010), 977-93.
} 
where the manifold mechanisms of configuring ever different and divergent masculinities in the discursive condition becomes readable, knowable, and thereby also rewriteable.

However, as the very concept of "configuration" evokes and as the following analyses which make up this volume will show, it is not necessarily the autonomous subject that in a creative act configures or constructs their masculinity. More often, it is the social and historical context and the existing power structures which configure the subject and their masculinity. Notwithstanding the question as to the agency of the subject, what is of importance here is that in literary texts, we find both, self- as well as externally-determined or enforced configurations of masculinity as well as the very mechanisms of their production or enforcement.

The articles collected in this volume not only offer analyses of how literary texts and the manifold worlds they represent (or, to be more precise, produce) configure masculinity, but also provide the theoretical framework for this undertaking, starting with Todd Reeser's conceptual history of the study of masculinity in the Englishspeaking Academy. Reeser's in-depth survey not only ranges from the birth of "men's studies" in the 1980's to current work on global masculinities, including work on the relations between masculinity and homosexuality, women, transgender, race, colonialism, and ethnicity, his contribution also expressly stresses the link between gender identity and literature:

In nearly all cases, questions of identity - whether cultural or individual - are central to masculinity studies, meaning that approaches to flesh-and-blood human beings and approaches to literary representations are not fully distinct. Sociological or anthropological understandings of masculinity can be and were in many ways imported to literary studies: literary constructs of masculinity may validate conceptions of gender in the social sciences, but literariness may also transform such conceptions in ways that only take place within the fictional text. ${ }^{19}$

The theoretical and conceptual framework which Reeser's text unfolds is further enhanced by Raewyn Connell's article "Masculinities: The Field of Knowledge" and Richard Collier's "On Reading Men, Law and Gender: Legal Regulation and the New Politics of Masculinity".

\footnotetext{
${ }^{19}$ See p. 13 of this volume.
} 
What these contributions also have in common is that, according to their specific scientific discipline and perspective, they offer different yet complementary definitions of and approaches to masculinity.

While Connell critically comments on the body of international masculinities research of the last twenty-five years, identifies the most important conclusions, and argues that men are most likely to change their gender practices when social justice as well as gender diversity (or de-gendering) are emphasized, Collier explores how an engagement with masculinity has developed in the field of legal studies almost unbeknown to many gender and masculinity studies scholars. Collier argues that particular ideas concerning men and masculinity have been constituted as distinctive "social problems" for law at varying historical moments and explores the relation between the law and masculinities in the context of debates about the politics of fathers' rights, a topic which is taken up again in Daniel Luke's article on fatherhood in The Book of Dave.

The contributions in the second and major part of this book take up the theoretical premises outlined by Reeser, Connell, and Collier, combining literary and cultural studies approaches with approaches currently deployed in masculinity studies, gender studies, legal studies, postcolonial studies, and cognitive psychology, to name but a few. The articles aim at elucidating how masculinity has been conceived and constructed within literature over a period of more than six centuries and how certain concepts of masculinity were created and continue to be created by the cultural systems and forms of knowledge underpinning literary discourse. As has already been indicated, literature is thereby understood as a productive and interactive medium by which a given society is not only reflected and critically reflects itself, but is actively shaped as well.

Including texts by canonical and established authors such as Thomas Malory, William Shakespeare, Henry Mackenzie, Thomas Hardy, John Osborne, John Braine, Allan Sillitoe, Ian McEwan, Caryl Phillips, Will Self, and Hanif Kureishi, Configuring Masculinity can be read as an exemplary diachronic analysis of varying configurations of masculinity in British literature. However, the literary production of six-hundred years can never be adequately represented by a few selected key texts only. Therefore, the main focus of this book cannot be on its diachronic or historical dimension: Configuring Masculinity is not meant to be a literary history. 
Nevertheless, texts such as Malory's Morte Darthur, Shakespeare's As You Like It, Mackenzie's The Man of Feeling, or Hardy's Jude the Obscure can open up a historical perspective which makes paradigmatic comparisons and the highlighting of similarities possible, while also displaying the differences and changes which configurations of masculinity have undergone over time. Thus, the diachronic dimension of the exemplary texts analyzed should make it possible to relativize presuppositions premised on archetypical patterns, on universal deep structure conflicts, and on biological determinism, thus enabling us to inquire whether the phenomena and configurations dealt with are not, in fact, indicative of and possibly restricted to a given age and cultural context.

In this sense, it should become possible to demonstrate that the instability of modern male gender identity can be understood as the consequence of historical processes, and male sexuality as a changing and historically conditioned product that has been falsely regarded as a natural constant. ${ }^{20}$ Therefore, the contributions analyzing the texts of Malory, Shakespeare, Mackenzie, and Hardy create an important historical backdrop, a temporal horizon before which the twentieth- and twenty-first-century texts, which make up the main part of this volume, can be more rewardingly analyzed than from a merely synchronic point of view.

Given the savoir litterraire or specific quality of literary texts briefly outlined above, it is not surprising that the analyses gathered in this volume furnish proof that texts which were written centuries ago still speak to us today: while Christoph Houswitschka's reading of Thomas Malory's Morte Darthur focuses on the timeless role of the male body, its importance for maintaining a strong masculinity, and the threats to which it is exposed, Mark Bracher's reading of Shakespeare's As You Like It convincingly illustrates how this Early Modern comedy offers a cogent critique of dominant masculinity together with a strong case for embracing alternative masculinity scripts that are less harmful to others and more fulfilling to their bearers themselves. Bracher repeatedly emphasizes the timelessness or extratemporality of literature, arguing that: "The first step in answering the question of how literature, and especially Shakespeare's As You Like It, might

\footnotetext{
${ }^{20}$ See Walter Erhart and Britta Herrmann, "Der erforschte Mann?", in Wann ist der Mann ein Mann? Zur Geschichte der Männlichkeit, eds Walter Erhart and Britta Herrmann, Metzler: Stuttgart 1997, 12.
} 
help us to overcome opposing and outdated scripts of masculinity is to understand the effects that Shakespeare's theatrical script can have on the cognitive scripts that variously constitute and determine readers' definition, understanding, evaluation, and enactment of masculinity." 21

While Bracher draws on cognitive psychology and uses the contemporary concept of internalized gender scripts to read Shakespeare, Rainer Emig stresses the relevance which The Man of Feeling has for contemporary society by arguing that in Mackenzie's country gentleman "Harley" we can see a trial run of modern masculinity, or rather of the various acceptable shapes of modern masculinities. My own metaphorical reading of Thomas Hardy's nineteenth-century novel Jude the Obscure advances a semiotic and Lacanian approach to demonstrate that the problems Hardy's protagonist Jude Fawley faces when constructing his male gender identity are by no means simply caused by or restricted to the social conditions of the nineteenth century, but rooted in Jude's fatal and fundamental misunderstanding of how signs work.

The analyses dedicated to literature of the twentieth and twentyfirst centuries, and therefore to highly contemporary configurations of masculinity, focus on texts by Ian McEwan, Will Self, Hanif Kureishi, Caryl Phillips, and others - on texts that are so popular that they more or less directly interfere with, and even shape, contemporary postmodern and postcolonial society and its concomitant constructions of male gender identity. In his contribution on the rise of the workingclass hero, Sebastian Müller argues that the "original angry young men", Jimmy Porter (Look Back in Anger) and Joe Lampton (Room at the Top), are not only in a class conflict, but also a gender conflict. Nevertheless, both of them "produce" themselves as typical workingclass heroes and follow a male role-model which provides a simple but effectively reaffirming mode of male identity formation in a twentieth-century world of shifting identities.

In her contribution on Ian McEwan, Fatemeh Hosseini emphasizes McEwan's obsessional, steady sketching and re-sketching of masculinities. She analyzes the portrayal of masculinity in a post-patriarchal era, the way it is intertwined with the thematic motif of death, and the emergence of a new socio-cultural era characterized by what she terms "filiarchy".

${ }^{21}$ See Mark Bracher's article in this volume, pp. 98-99. 
The next two articles deal with postcolonial, and to some degree, postethnic masculinities: Bettina Schötz's essay analyzes how Hanif Kureishi's postethnic short stories explore contemporary configurations of masculinity by depicting the disruption of traditional, patriarchal, and hegemonic notions of masculinity in the postfeminist era and imagining alternative forms of male gender practice. Moreover, Schötz argues in favor of a specific savoir littéraire, for example in Kureishi's "Morning in the Bowl of Night", and suggests a definition of masculinity based on a critical reading of both, Judith Butler and Elizabeth Deeds Ermarth.

In her article "Of Invisible Men and Native Sons: Male Characters in Caryl Phillips' Fiction", Bénédicte Ledent takes the prominent male presence in Phillips' In the Falling Snow as a starting point for an analysis of the relative deficit in masculine visibility in his earlier fiction, for example in texts such as The Final Passage or A Distant Shore. She argues that the male presence in In the Falling Snow not only begs for a re-examination of the male figures in Phillips' earlier work but also calls into question the dichotomies that often permeate conventional approaches to gender.

In the last contribution to this volume, Daniel Lukes' "Surrogate Dads: Interrogating Fatherhood in Will Self's The Book of Dave", the question of fathers' rights are taken up once again. Luke argues that The Book of Dave develops Self's ongoing interest in fathers, children, and fatherhood as a key nexus where masculinity and patriarchy are reproduced. Moreover, he depicts how the novel engages and interrogates matters of paternity, patriarchy, power, the religions of the father, the malaise of millennial British working-class masculinities, and the question of what it might mean to be a post-patriarchal dad. 